Comunicação e Sociedade, vol. 17, 2010, pp. 17-30

\title{
Ruídos do fotográfico no imaginário digital
}

Victor Manuel Esteves Flores*

Resumo: Este ensaio debruça-se sobre a cultura do fotográfico que as imagens técnicas vieram desenvolver, visando, em particular, o modo influente pelo qual essa cultura criou fortes paradoxos na actual evolução da imagem digital. Um desses paradoxos mais "visíveis" prende-se com a convocação por parte das actuais práticas da imagem digital de ruídos e distorções visuais próprios ao regime visual anterior, o analógico. Este facto, que muito nos diz sobre a actual cultura visual, deve antes de mais permitir-nos questionar sobre o peso que a qualidade da imagem (ou seja, a sua nitidez e definição) teve na emergência e aceitação social de cada novo medium visual. Em segundo lugar, irá permitir-nos avaliar o peso dos ruídos visuais na cultura do fotográfico, assim como na sua respectiva incorporação pela cultura digital e pelas suas diferentes interfaces. Tal como sucedeu no projecto visual moderno, os ideais de semelhança, transparência e nitidez convivem hoje tranquilamente com ruídos próprios ao "fotográfico", dando conta de como uma cultura visual das lentes continua a interferir no actual imaginário digital, e, desta vez, não por razões técnicas mas sim retóricas.

Palavras-chave: imagem digital, ruído fotográfico, confiança, remediação.

\section{Introdução}

É cada vez mais notório o modo como a cultura visual contemporânea está a ser colonizada por ecrãs e interfaces digitais responsáveis por uma gradual transposição dos dados em infografias, dos pensamentos e da imaginação em animações 3D. Sabemos que estas imagens são altamente dinâmicas, actualizáveis em tempo real e, entre outras qualidades, interactivas com o corpo do utilizador. A eficácia desta "colonização" deve-se sobretudo a uma anterior e forte convivência do homem moderno com as imagens,

\footnotetext{
* Universidade Lusófona de Humanidades e Tecnologias, Escola de Comunicação, Artes e Tecnologias de Informação, victor.flores@sapo.pt.
} 
designadamente com as imagens técnicas, e ao facto de há muito terem sido projectadas nelas fortes expectativas que as fizeram valer como meio de conhecimento, de controlo e também de comunicação. É verdade que a imagem foi uma das primeiras “aplicações comunicacionais" de sempre, e tal deveu-se ao facto de nela se pressentir desde cedo a possibilidade de um contacto. "Semelhança", "transparência", "nitidez" foram sendo ao longo dos tempos os termos que faziam ecoar esse desejo histórico - e mágico! - de contacto, ou seja, de uma presença que a imagem parecia restituir. Mas nem sempre esta semelhança e esta nitidez estiveram isentas de ruídos no seio daquela que foi uma cultura visual das lentes. Se, por um lado, as lentes aproximam e garantem a focagem, por outro, distorcem e desfocam. Foi neste jogo de forças próprio a uma cultura das lentes que a cultura visual moderna se estruturou, influenciando ainda o modo como as novas imagens e os novos interfaces constroem as suas ilusões de contacto. É decisivo para uma história ou teoria das interfaces uma reflexão sobre o quanto dessa cultura visual moderna, designadamente o aspecto das imagens e alguns dos efeitos ruidosos das suas lentes, foi convocado para o seio das novas aplicações como garantia de familiaridade e de confiança visual. As novas ilusões de contacto resultam de negociações e de permanentes pesquisas de soluções de compromisso entre "afinações técnicas” e ruídos visuais. Interessa-nos o quanto as imagens digitais não prescindiram do visual fotográfico, esse terreno (con)sagrado na percepção visual moderna, precisamente porque é aí que constroem parte da sua estética e retórica visual. Mas desde quando é que a nitidez e o grau de definição da imagem são, efectivamente, um critério de eficácia comunicacional e de melhor penetração social de um novo medium visual? O cinema parece-nos pois um bom exemplo para começar...

\section{Distorção visual e confiança}

No início do seu livro L’Oeil interminable, Jacques Aumont confronta-se com os relatos de imprensa que descrevem as reacções dos primeiros espectadores dos filmes Lumière e deixa-se surpreender por uma conclusão: “(...) de todos os relatos que li, nenhum para se queixarem, muito pelo contrário, de não terem visto senão uma imagem cinzenta” (Aumont, 1995: 22). Este seu reconhecimento da aparente inobservância do cinzentismo da imagem pelo público que acompanhou o nascimento do cinema parece dar conta de uma certa predisposição cultural para este grau de qualidade e - arriscamos dizer - de "definição" das imagens no início do século XX. Se por um lado essa predisposição deve ser articulada, segundo Aumont, com o trabalho desenvolvido durante todo o século XIX pela pintura e pela fotografia em torno dos efeitos atmosféricos, ou seja, da representação da luz e do ar ("os Lumière descendem do impressionismo", defende), por outro, essa "predisposição para o cinzentismo" pode ser também entendida como um efeito colateralmente suscitado pelos novos entusiasmos que o cinema veio provocar. Trata-se não tanto de entusiasmos da ordem do susto desencadeado pelo filme L'Arrivée d'un train en gare dos irmãos Lumière, mas antes do interesse despertado pelos pequenos detalhes efusivamente apreciados e descritos nestes relatos. São pequenos e simples pormenores visuais que inadvertidamente funcionaram como efeitos de realidade: 0 
movimento cadenciado das ondas do mar, a deslocação de folhas, as baforadas de fumo, assim como também a diversidade das imagens - a sua não repetição -, o deslumbre pelas consecutivas descobertas de pormenores e figurantes nos segundos visionamentos. ${ }^{1}$

A avaliar por estes relatos, o verdadeiro efeito de surpresa do cinema reside nesta poética que aprimorou as primeiras moving pictures, nestes novos efeitos de real "inocentemente perfeitos", e que em todo o caso vêm sistematizar as preocupações visuais do século XIX em torno do impalpável, do irrepresentável e do fugitivo com as quais a pintura se envolveu. Este foi, segundo Aumont, o modo pelo qual o cinema se colocou como herdeiro da pintura, erigindo a luz e o ar como objectos picturais, como paradigmas do realismo. O investimento cinemático nestes efeitos parece pois ter sido suficiente para que o próprio cinzentismo viesse a resultar não tanto como um ruído mas como uma acentuação do ambiente e do clima nos quais esses mesmos efeitos de realidade operavam. Provirá provavelmente daí a ausência de lugar para a sua estranheza, e a confirmação da sua "legitimidade".

Este caso parece-nos não ter estado circunscrito ao cinema mas ser antes paradigmático dos momentos de emergência das várias imagens técnicas. Isto porque não parece ter sido a qualidade da imagem que alguma vez motivou a emergência de um novo meio de comunicação visual, ou que tenha sequer sido a característica que mais tenha surpreendido o seu primeiro período de recepção. Pelo contrário, houve soluções tecnológicas particularmente focalizadas na qualidade da imagem que foram retidas, muitas vezes pendendo sobre esta retenção o argumento sobre a fraca expressão social dessa necessidade. De um modo geral, o início da fotografia, do cinema e da televisão, apesar do marco tecnológico assinalado, caracterizou-se pela projecção de imagens turvas, pouco contrastadas e de muito baixa resolução. Todavia, se a cultura impressionista preparou para a fotografia e para o cinema um mercado visual treinado para lidar com ruídos e imagens trémulas, o mesmo não se aplica no caso mais tardio da televisão. O que permitiu então o seu lançamento, designadamente o início das suas emissões regulares (entre, aproximadamente, 1935 e 1957), num mercado visual agora experiente em imagens bem definidas providenciadas quer pela fotografia quer pelo cinema?

Esta questão foi desde cedo trazida a lume em 1964 por Marshall McLuhan em Understanding Media. De acordo com McLuhan, apesar de a televisão poder ser entendida como uma extensão dos filmes de cinema (um medium considerado "quente" pelo modo como prolongou a visão humana), um dos factores que a qualificavam como um medium "frio" era precisamente o facto de a qualidade de definição da sua imagem ser substancialmente inferior à dos filmes projectados nos cinemas, exigindo por isso que o espectador preenchesse mais detalhes com a sua imaginação. De facto, não foi a

\footnotetext{
${ }^{1}$ A avaliar pelo investimento que a computação gráfica tem feito nos últimos anos em temas relacionados com a natureza, o fascínio por estes elementos parece, de facto, ter-se perpetuado até aos nossos dias. Lev Manovich descreve a incidência destes "signos privilegiados do realismo" numa das instalações apresentadas nas conferências SIGGRAPH: Moving Nature, onde a natureza em movimento se faz sentir pela representação digital do vento, das ondas e do fumo, da erva a mexer-se com o vento, e do fogo (Manovich, 2001: 196). De resto, o investimento nestes signos está intimamente relacionado com a natureza militar de uma grande parte das investigações computacionais, incidindo com particular perseverança no "tema" da paisagem devido à sua utilidade para os treinos em simuladores.
} 
qualidade da imagem que motivou a emergência da televisão. Tal viu-se inclusive reflectido numa das principais tendências que nortearam a tradição europeia de investigação televisiva, designadamente o cepticismo relativamente às capacidades expressivas e estéticas da televisão. Se, por um lado, este cepticismo resultou de um impulso excessivo de comparação da televisão com o cinema (compreensível aliás pelo facto de ser ao cinema que estavam vinculados os principais teóricos da imagem em movimento), por outro, quer as imperfeições que caracterizavam a imagem, quer a sua vertente comercial ${ }^{2}$, faziam com que a televisão fosse muitas vezes apenas encarada como um dispositivo de publicidade. Deste modo, as reflexões sobre a qualidade da imagem televisiva surgiram sempre no quadro de uma crítica que raramente se autodesignou como "estética", e tal deveu-se precisamente a um continuado questionamento sobre a validade estética das imagens televisivas ${ }^{3}$.

Mas, se a imagem emitida por este novo meio de comunicação se oferecia esteticamente problemática, já a transmissão em directo e à distância de imagens em movimento veio cristalizar-se como $a$ vantagem que desautorizava quaisquer comparações depreciativas com os media visuais anteriores. Esta era a "especificidade televisiva absoluta". E esta vantagem era tão decisiva quanto considerada improvável pelo grande público. A ilustrá-lo estão alguns dos seus episódios inaugurais, dos quais destacamos a primeira emissão televisiva norte-americana da empresa RCA na Feira Universal de Nova Iorque de 1939. Esta emissão foi transmitida num aparelho que consistiu numa grande caixa em paralelepípedo que havia sido mandada fazer - para efeito exclusivo daquela exposição - em materiais transparentes que dessem a ver o seu interior: o expediente encontrado para dissuadir as generalizadas suspeições de embustes mágicos que à época pairavam sobre uma “transmissão em directo". Para todos os efeitos, a organização preparou uns cartões-certificado para quem se deixasse filmar, facto que ainda assim não veio impedir que a imprensa apelidasse o aparelho de "Phantom Receiver".

Com efeito, é precisamente em torno do directo que o contributo estético da televisão vem a ser avaliado (Bazin, 1955 ou Eco, 1989). Pese-se embora estas contrariedades estéticas - muito vincadas por dificuldades em ajuizar a qualidade de imagens que funcionavam "em fluxo" -, o início da televisão coincide de facto com uma fase em que os graus de definição de imagem da fotografia e do cinema já gozavam de uma apreciável estabilidade. A sua verdadeira mais-valia foi antes a experiência da simultaneidade e da edição síncrona.

\footnotetext{
${ }^{2}$ A BBC era a única verdadeira excepção de um serviço público suportado exclusivamente pelo Estado. A maior parte dos restantes modelos europeus, incluindo o português, lançou-se como "misto".

${ }^{3}$ Uma parte significativa do ensaísmo dos anos 60 reflecte esse cepticismo quanto às potencialidades estéticas da televisão: André Bazin, no seu ensaio "L'avenir esthétique de la télévision: la télévision est le plus humain des arts mécaniques" de 1955; posteriormente Umberto Eco, na sua A Obra Aberta de 1962, ou ainda, entre outros, René Lindekens no texto "La naissance difficile d'un huitième art" em 1965. De resto, este reconhecido fraco aproveitamento das capacidades expressivas da televisão vem inclusive a tornar-se o leitmotiv inaugural da arte vídeo nos anos 60. A denominada "televisão de guerrilha" vinha precisamente contrapropor novos "desenhos com o tubo de raios catódicos", de acordo com a designação com a qual Nam June Païk situou o seu trabalho. No rescaldo deste posicionamento crítico inicial à televisão, a estabilização da televisão como um objecto sistemático de estudos só virá a acontecer a partir de meados dos anos 70. Tal não veio porém evitar que alguns investigadores contemporâneos da televisão ainda reconheçam que a imagem permanece o território impensado da televisão (Wolton, 1994).
} 
De um modo não muito diferente, nos nossos dias, as projecções de alta definição convivem com as imagens que nas novas aplicações são comprimidas, ou seja, simplificadas algoritmicamente (resultado da designada lossy compression), a ponto de se poderem tornar irreconhecíveis e estranhas ao próprio fotógrafo. Outras vantagens se sobrepõem ou se antecipam para que a sua sobrevivência se justifique, nomeadamente novas funcionalidades com que cada imagem surge associada, capacidades de consolidar grupos e relações interpessoais no seio de um grande público, de gerar dinâmicas e fazer marcações na vida social e privada, de encurtar distâncias, de recriar o visível. O olhar humano é facilmente seduzível por estas novas extensões visuais que as aplicações técnicas lhe oferecem mesmo que a custo da qualidade da resolução da imagem implicada nessas operações.

Esta solução de compromisso está fortemente enraizada a ponto de se ter naturalizado culturalmente. O gradual desprendimento pela qualidade com que a imagem representa o fotografado em prol da rapidez, do preço e da eficácia do envio/recepção, tem-se tornado por demais evidente. Se é verdade que os novos usos tecnológicos a que nos fomos habituando no campo da imagem (fotografia e vídeo dos telemóveis, troca de ficheiros de imagens pela internet; streaming video) tornaram mais prática e quotidiana a produção e o envio de imagens, é também verdade que foi tecnicamente necessária uma considerável redução na definição da imagem. Ainda não há muito tempo, grande parte das imagens que guardávamos nos computadores e que trocávamos pelos telemóveis era muito comparável (no rácio tamanho/definição) às primeiras imagens da televisão mecânica ${ }^{4}$. Tal veio ratificar o facto de que o "realismo", uma das qualidades desde cedo reconhecidas às imagens técnicas, nem sempre coincidiu com a nitidez visual, situando-se muitas vezes para além das suas margens territoriais.

O realismo relaciona-se assim também com o conjunto dos efeitos de real que ao longo da história das imagens técnicas já deram pelo nome de cor, movimento, profundidade de campo, tridimensionalidade, rapidez, instantaneidade e, entre outros, interactividade. $\mathrm{O}$ que significa a nitidez da imagem tender a não ser aferível como um efeito de realidade prioritário? O que é que isto pode dizer da cultura fotográfica em que nos incluímos? Antes de mais, dá a entender que os ruídos que resultam dessa ausência de nitidez, habitam e dão forma a um significativo quarteirão da cultura do fotográfico. Sabemos hoje que se trata de um quarteirão influente e que a maior parte das vezes não é percepcionado ou verdadeiramente entendido como "ruído". Até porque sempre que o ruído for realmente entendido como tal ele é dificilmente tolerado. Ora, os modos pelos quais esta "solução de compromisso" se enraizou culturalmente interessa a uma teoria da imagem técnica na medida em que determinados ruídos técnicos parecem ter sido incorporados e, por essa mesma via, tornados inalienáveis a uma cultura do fotográfico.

\footnotetext{
${ }^{4}$ As primeiras imagens televisivas de John Logie Baird, o responsável pelo sistema que a BBC viria a utilizar na sua primeira transmissão em 1929, datam de 1925 e recorriam ao célebre disco de Nipkow (patenteado pelo investigador alemão Paul Nipkow em 1883). Eram ainda imagens pretas e vermelhas devido à cor do gás néon na lâmpada, e tinham uma definição de trinta linhas a que correspondia inevitavelmente uma imagem muito pequena (aproximadamente, seis centímetros de altura por dois centímetros de largura).
} 
Uma das principais razões do alcance desta ligação reside no facto de a cultura do fotográfico assentar numa cultura das lentes com que o mundo ocidental se deixou implicar ainda muito antes do surgimento da fotografia. Este envolvimento pré-fotográfico com as lentes e a sua consolidação cultural em meados do século XVI permitiu que o interesse pela percepção visual, pela óptica e pelas lentes desencadeado junto da ciência, mas também da filosofia, da literatura ou das artes plásticas, fosse também um interesse pela prevenção das distorções, das desfocagens, em suma, das "zonas de invisibilidade". Todo este esforço de prevenção fez inclusive com que a palavra "objectiva” passasse a designar o dispositivo que integra a lente. A transparência do seu vidro veio igualmente contribuir para que a interpretassem como neutra. Mas, a par deste discurso, ao fazerem coincidir o seu processo de captação de luz com o uso de lentes, as imagens técnicas ganharam desde cedo uma particular afinidade com o ruído óptico, isto é, com as distorções e deformações que são próprias a uma lente sempre que reduz ou amplia, sempre que tem o terceiro plano focado com grandes aberturas, sempre que o movimento é demasiado veloz.

Deste modo, o que a longa história de uma cultura das lentes veio significar foi que esses ruídos ou distorções não só tenderam a tornar-se inapreensíveis ou transparentes como também vieram a ser um forte contributo para essa mesma transparência. Ou seja, eles chegam, paradoxalmente, a funcionar como um dos mais eficazes efeitos de real das imagens técnicas. E tal sucede por se terem feito introduzir de um modo mais ou menos insidioso na sua linguagem, na sua retórica e na sua massa híbrida de produtos, funcionando muitas vezes como remediações, ou seja, como alusões implícitas a experiências visuais consolidadas. Com efeito, a captação de um aspecto imperfeito, quase ilegível, tende cada vez menos a ser pressentida como falsa ou irreal. A sua eventual e muito provável rejeição tem a ver mais com determinada ordem específica de critérios estéticos, em alguns casos com necessidades de inteligibilidade, do que propriamente com verosimilhança.

Das imagens altamente abstractas das ecografias em que o "ruído sonoro" que constitui a fonte de informação para a imagem é altamente proporcional ao ruído visual em torno do qual a imagem se estrutura, às imagens nocturnas de infravermelhos que varrem as cores e que se vulgarizaram nas câmaras amadoras de vídeo ou nos quartos escuros dos reality shows, às fotografias desfocadas dos paparazzi da imprensa cor-de-rosa, ou ainda ao cinema da câmara ao ombro que o novo documentarismo tem celebrizado, as distorções são normalmente interpretadas como uma representação mais "profunda", ou seja mais crua e correspondente da realidade, equivalendo grosso modo à presunção de uma ausência de artifícios, ou seja, a uma sensação de contacto com uma matéria em estado bruto. No fundo, equivalendo a um contacto com uma "textura" dos corpos e das superfícies. Diríamos assim que o ruído serve afinal para impregnar a imagem de vestígios, de relações até extravisuais que a tornam mais próxima e íntima do que representa, traduzindo a agitação em torno da qual o real se organiza e se predispõe enquanto imagem.

Tal como reconhece Martine Joly (2003), nem sempre a invisibilidade ou a má visibilidade são conotadas com ruídos, com desconforto ou com imagens fracassadas. Há 
pois certos contextos comunicacionais que implicam outras convenções de verosimilitude, estipulando "a má visibilidade" como "uma prova suplementar de autenticidade" (Joly, 2003: 95). Este é inclusive, segundo Joly, um dos expedientes a que a retórica das imagens técnicas se socorre em determinadas situações mais agudas de "comprovação", desfocando, por exemplo, as caras das testemunhas de um crime, ou das vítimas de violência.

\section{Evoluções técnicas e compromissos sociais}

Ainda hoje haverá dificuldade em reconhecer que a evolução da imagem foi construída com base em cedências e compromissos de qualidade em prol de certos artifícios aferidos como prioritários em determinadas épocas. A emergência e o desenvolvimento das tecnologias do olhar, como Brian Winston (1996) as descreve, resultou de um contínuo exercício de adição e de subtracção de efeitos de real viabilizados tecnicamente, sendo que os critérios que regularam esse "exercício" resultaram não poucas vezes de fortes pressões por parte de determinados campos da indústria da imagem.

O cinema afigura-se nesta questão como exemplar, e isto porque sempre se associou à promoção das inovações técnicas, muitas delas resultantes da investigação militar (tais como as lentes zoom, o cinerama, as câmaras 3D, etc.). Um dos factores que desde cedo contribuiu para a caracterização do cinema de Hollywood como indústria foi o facto de tanto ter servido como laboratório de ensaio, como de plataforma de lançamento para os novos produtos que foram funcionando como suplemento para as imagens em movimento: o som, a cor, os grandes ecrãs, o 3D, o som estereofónico, etc. Esta tendência consolidou-se na actualidade a ponto de, tal como descreve Lev Manovich (2001: 190), os filmes de animação serem desenhados para exibir o último algoritmo.

Um dos casos que mereceu uma particular atenção por parte da teoria do cinema (Bazin, 1958; Comolli, 1971-1972; Bordwell, 1988) foi o da intermutação entre a cinematografia de profundidade de campo e a cinematografia de focagem difusa no primeiro meio século do cinema. Estas cinematografias estão directamente relacionadas com as capacidades técnicas de captação e de representação do espaço, permitindo ou não ter o primeiro e o último planos simultaneamente bem definidos. O que desde sempre chamou a atenção para esta questão foi o facto de no período de 1925 a 1941, aproximadamente, ter preponderado uma cinematografia de focagem difusa, ou seja, ter sido lançada uma grande maioria de filmes cuja imagem apresentava um aspecto difuso e nublado (com um soft look, tal como o descreve Bordwell (1988)), contrastando com o período anterior em que se situam os filmes fundadores do cinema, e também com o período posterior (a data de 1941 é um momento de viragem porque marca o lançamento de Citizen Kane de Orson Welles reconhecido pela grande profundidade de campo dos seus planos).

Este período intercalar de 1925 a 1941 pode ser visto como um verdadeiro intervalo às filmagens de focagem nítida. Por coincidência, este é também o período em que o cinema tanto passa a recolher o som, como passa a utilizar a película pancromática, uma película cuja emulsão era sensível a toda a luz visível, permitindo aberturas menores do 
diafragma e, logo, uma maior profundidade de campo. Para trás ficaria a película ortocromática, apenas sensível às radiações do azul e do violeta e adequando-se a objectivas com maiores aberturas. Contudo, ao contrário do que estes meios técnicos disponíveis deixariam esperar, estes primeiros anos do filme pancromático constituem, paradoxalmente, o período de interrupção da profundidade de campo - "o esfumado dos segundos planos era geralmente de rigor”, reconhece Bazin (1958: 79). A razão desta ocorrência nem sempre foi consensual na teoria do cinema, alegando-se muitas vezes razões relacionadas com o novo "conjunto técnico" que o pancromático exigia. Autores como Mitry explicam este efeito de perda de profundidade de campo como uma inadaptação dos sistemas de iluminação ao espectro desta emulsão ${ }^{5}$. Ora, as razões da menor profundidade desta cinematografia encontraram argumentos com maior alcance e plausibilidade em autores como André Bazin (1958) ou Jean-Louis Comolli (1971-72). Ficou bem conhecida na teoria do cinema a extrema valorização da profundidade de campo e do plano-sequência por Bazin, tendo-os associado à imagem retiniana e à "vocação realista do cinema". De acordo com Bazin, a exclusão da profundidade de campo não se deveu a uma questão técnica mas a uma questão de estilo (ou como o explicita "de procura de estilo" (Bazin, 1958: 79)). Estilo este que Bazin (1958: 82) virá a associar à sua crítica à montagem:

O esfumado na imagem só apareceu com a montagem. Não era apenas uma servidão técnica consecutiva ao emprego dos planos comparados, mas a consequência lógica da montagem, a sua equivalência plástica. (...) O esfumado dos segundos planos confirma pois o efeito da montagem, só acessoriamente pertence ao estilo da fotografia, mas essencialmente ao da narrativa.

A posterior reacção de Comolli também não se socorre do argumento do "atraso técnico", defendendo antes que as alterações verificadas entre os anos 25 e 40 são sintomáticas de uma alteração dos códigos de realismo e de verosimilhança, exigindo-se outros desempenhos por parte do cinema que não passavam pela profundidade de campo. Ela deixou de ser sentida como necessária, tanto assim que, tal como afirmou Comolli (1972: 95) reportando-se ao exemplo de Jean Renoir, “bastava querer” para filmar em profundidade. Tal como o expunha em 1971:

A profundidade de campo não estava "na moda" em 1896, ela era um dos factores de credibilidade na imagem cinematográfica (como, mesmo senão pela mesma razão, a reprodução fiel dos movimentos e a analogia figurativa). E é pela transformação das condições dessa credibilidade, pelo deslocamento dos códigos do verosímil cinematográfico do plano isolado da impressão de realidade aos planos mais complexos da lógica ficcional (códigos do argumento), do verosímil psicológico, da impressão de homogeneidade e de continuidade (o espaço-tempo coerente do drama clássico), que poderemos dar conta do apagamento da

\footnotetext{
${ }^{5}$ A posição de Mitry é assinalada por Comolli nos Cahiers du cinéma (Comolli, 1971) e é o reconhecimento de que o pancromático apresentava uma sensibilidade desigual à luz, exigindo que nos estúdios (o local preferido para as filmagens deste período, por motivos técnicos e financeiros) se adoptasse um novo tipo de iluminação (incandescente) que, por ser menos potente, requeria maiores aberturas do diafragma.
} 
profundidade de campo, e não unicamente pelos "atrasos" técnicos, porque estes "atrasos" não são acidentais, são eles próprios parte e efeito desse deslocamento, dessa substituição de códigos. (Comolli, 1971: 43)

$\mathrm{O}$ que tornou este caso um paradigma dentro do tema da nitidez da imagem foi o facto de destacar um período significativo da história do cinema do século XX em que o realismo e a verosimilhança visual puderam prescindir da profundidade de campo por se ancorarem noutros artifícios. Tenha sido a novidade do som, a intensidade das tramas narrativas, a montagem e a sua muito criticada "fragmentação intensiva do real", a sofisticação dos cenários ou ainda o crescente estrelato dos actores, não deixa de ser notório que houve um momento em que a desfocagem (ou a menor nitidez da imagem) se pôde tornar uma opção de estilo, e que tal só poderia ter ocorrido por via de proveitosas compensações para o espectador, de forma a que este não visse o soft look como uma falha. Também neste caso estamos perante novas extensões do visual que simulam a experiência com outras impressões de realidade, compensando, de várias maneiras, a imagem degradada.

Um dos principais pontos de interesse em retomar este episódio marcante na construção visual dos regimes de realismo no cinema reside na oportunidade de detectar as marcas profundas que ele deixou na cultura visual das imagens técnicas. Pelo facto de a melhoria da definição das imagens ter sido um objectivo constante, os ruídos na história do cinema sempre funcionaram no âmbito de soluções de compromisso. A erradicação de uns estava na origem de outros, tidos neste ou naquele momento como males "suportáveis" para a viabilização do "aceitável aspecto de realidade". Os objectivos de ilusionismo, apesar de terem sido uma das principais obsessões que ocuparam a actividade das máquinas ópticas e da cultura de massas, nunca se puderam definir por transparências totais.

Ora, esta sustentada história de ruídos teria nos dias de hoje a sua morte anunciada perante a emergência do digital ou, mais propriamente, perante a possibilidade de digitalização dos sinais analógicos. E isto porque, apesar de a extracção do ruído ter sido um dos objectivos capitais das técnicas de tratamento da captação e transmissão do sinal analógico (uma das principais preocupações que norteiam a Teoria Matemática da Comunicação de Claude Shannon de 1948), com a digitalização dos sinais conseguiu-se ultrapassar uma das principais dificuldades anteriormente sentidas, designadamente a separação e a distinção das representações do sinal das dos ruídos (para sermos mais precisos no que respeita à terminologia, trata-se da distinção entre, respectivamente, a informação considerada "útil" e a informação considerada "não útil”, e isto porque os ruídos são também sinais). A esta possibilidade de representação gráfica e de processamento dos sinais acresce ainda o facto de a filtragem de ruídos poder ser feita logo na captação da informação, seleccionando-se na fonte a informação julgada útil, reduzindo-se assim as suas redundâncias. É esta selecção algorítmica de informações na fonte que tem sido responsabilizada pela perda do "carácter contíguo, bruto e aberto do índice” (Barboza, 1996), mas também por um aumento considerável da qualidade da imagem e da sua transmissão. 
Perante este cenário promissor para a erradicação dos ruídos ou dos sinais indesejados, quando consideramos as imagens digitais ou as aplicações vídeo de alta definição, o factor "ruído" soa improvável e contraditório. Fazem parte da alta definição imagens com qualidade quatro vezes superior resultante de uma resolução até às 1080 linhas. Anuncia-se ainda a eliminação da cintilação do ecrã própria aos padrões anteriores de varrimento. Os novos leitores de DVD Blu-Ray estão habilitados a processar por segundo cerca de quinze mil milhões de pixéis. Contudo, a toda esta extraordinária viragem exercida sobre os padrões de definição da imagem electrónica estabilizados há mais de meio século, o digital não se pôde ainda desvincular dos ruídos e das distorções que, quase sempre "por defeito", foram engendrando o padrão de realismo a partir do qual se alçou a cultura visual das imagens técnicas. Mas neste novo cenário não se trata tanto da dificuldade de extrair o ruído, mas sim da grande oportunidade de o poder acrescentar. Uma das principais vantagens normalmente catalogadas para o uso e a divulgação comercial deste novo padrão, designadamente nas filmagens, é o facto de capacitarem a adição em pós-produção de filtros (additive filtering) não só para a correcção da cor, mas também para, por exemplo, se criarem efeitos de arrastamento na imagem, ou seja, para se associarem ligeiras desfocagens (função motion blur) a cenários e últimos planos, criando assim um efeito actualmente descrito como "de envolvência", e que é perfeitamente reportável ao soft look dos anos $30^{6}$. Ora estas funções fizeram-se sentir nas imagens de síntese desde cedo. Pelo menos desde a década de 80 vêm sendo criados algoritmos para aligeirar o hiper-realismo da computação gráfica (desfocagem do movimento e da profundidade de campo; grão; contornos atenuados das figuras, etc.), e que se vulgarizaram quer nos menus dos sofisticados sistemas profissionais de edição (AVID, por exemplo), quer também nos mais vulgares softwares para o utilizador, muitas vezes sob a forma de "paletas de estilo" (efeitos blur, aguarela, sépia, filme antigo).

O facto de o ruído óptico estar a intervir na codificação do realismo digital implica que algumas imagens de síntese estão a ser programadas para autodissimularem a sua resolução infinita e o seu ilimitado grau de detalhe. $\mathrm{O}$ olhar que as acolhe foi adestrado pelo foto-realismo e pelos ruídos que a óptica (humana ou das lentes) deixou nas imagens e nas práticas visuais dos últimos séculos. Por essa razão, estes truques não só diminuem a perfeição visual como também aproximam a computação gráfica da visão natural e das suas respectivas codificações técnicas modernas e pré-modernas. Tanto é que a necessidade da sua utilização faz-se especialmente sentir quando se trata de combinar a imagem digital com a imagem fílmica. Ora, esta naturalização da imagem é uma ambição antiga. Remonta tanto à viragem da perspectiva aérea de Leonardo Da Vinci perante a "perspectiva artificial", como ainda às desfocagens nas pinturas renascentis-

\footnotetext{
${ }^{6}$ Apesar de ter sido filmado em 35mm, o recente filme de Steven Soderbergh O Bom Alemão, ao apresentar-se em 2006 como uma recriação de um filme pós-guerra (com Berlim reencenada a preto e branco), é um bom exemplo de como o efeito soft look ainda se fez sentir nesse período, e, mais ainda, de como este efeito não se nos afigura totalmente estranho nos dias de hoje. Este efeito não só resulta aqui de um recurso sistemático a imagens históricas de arquivo, como do facto de as próprias imagens de Soderbergh combinarem com aquelas através de uma contínua desfocagem do último plano. Ainda uma pequena anotação: a distribuição portuguesa não resistiu a introduzir mais um toque de realismo de época ao optar na legendagem por tipos de estilo antigo com pontos e manchas de ruidosa cintilação.
} 
tas que já recorriam à câmara escura. Desde muito cedo que a desfocagem, a imprecisão e o ruído visual participaram na cultura do ilusionismo, vindo a fixar-se nos nossos dias como um dos principais pilares do realismo das imagens técnicas tanto no documentarismo como na ficção industrializada. Se as crenças e as práticas de recepção do analógico exigem o "enfraquecimento" do digital - e da sua designada "artificialidade" -, sobrecarregam-no igualmente com um estilo "impróprio", ainda que muito próprio a um impulso de continuidade constante no surgimento de novos media (Thornburn \& Jenkins, 2003) ou, de igual modo, ainda que noutros termos, a uma estratégia de "remediação" que Bolter e Grusin (2000) defendem ser definidora da função contemporânea dos novos media digitais. A verdade é que assistimos a uma incorporação do ideal do foto-realismo por parte da imagem digital, e isto num momento em que esta já o ultrapassou tecnicamente. Este inevitável paradoxo nos padrões do ilusionismo das tecnologias digitais é por variadas vezes sublinhado por Lev Manovich (2001: 180) no seu livro dedicado à linguagem dos novos media:

O paradoxo da cultura visual digital é que, embora toda a imagem esteja a ser feita em computador, a predominância do imaginário fotográfico e cinematográfico está a tornar-se ainda mais forte. Mas, em vez de ser um resultado directo e "natural" da tecnologia fotográfica ou cinematográfica, estas imagens são construídas em computador. Os mundos virtuais 3D estão sujeitos aos algoritmos de desfocagem da profundidade de campo e do movimento; o vídeo digital é processado através de filtros especiais que simulam os grãos do filme, e por aí em diante.

Esta questão acaba por evocar o debate sobre as possibilidades de a imagem digital poder suplantar em realismo as imagens analógicas assentes nos princípios das lentes. $\mathrm{O}$ investimento e as oportunidades de aplicação estão hoje de facto a favorecer o digital. Apesar do significativo contributo ilusionista dos ruídos, o digital tem logo à partida a vantagem de assentar numa representação numérica, podendo por isso programar todas as suas imagens. Ora, isto altera profundamente a natureza do realismo mas também as potencialidades do seu alcance, isto é, do conjunto de efeitos que podem ser criados e combinados, a ponto de, tal como sugere Manovich (2001: 199), se poderem tornar "demasiado reais". Esta natureza hiper-real do digital está intimamente relacionada com a sua inerente desvinculação com estes efeitos passadistas das lentes pelo facto de as suas imagens estarem à partida isentas do efeito de profundidade de campo, isentas de grão, possuírem cores mais saturadas e linhas acentuadamente geométricas.

De facto, o horizonte futuro das aplicações digitais deverá orientar-se para o desenvolvimento e a consolidação de sensações realistas situadas para além das fronteiras do foto-realismo. Isto não significa, contudo, que a curto prazo o ilusionismo ou a fidelidade visual percam importância. Significa antes que serão cada vez mais viabilizados por simulações que tenham em conta outras dimensões da sensibilidade, as emoções ou ainda a interactividade. Uma grande parte do esforço das artes tecnológicas reside precisamente na criação de experiências artificiais que articulem o imaginário lens based com outras formas não visuais de atracção e de imersão do espectador. Tal vem significar que o 
imaginário da computação gráfica no seu estado "puro", i.e., limpo de ruídos e construído em torno de uma supervisão foi durante os primeiros tempos da consolidação das tecnologias digitais inevitavelmente conotado com o futuro, com o horizonte da ficção científica e da pura artificialidade. Esta é inclusive a iconografia em que se funda a figura do Exterminador 2, um mensageiro do futuro cujo corpo computado graficamente reflecte a realidade circundante de forma ultradefinida, limpa e sem desfocagem:

(...) para representar o Exterminador que vem do futuro, os designers usaram as técnicas standard da computação gráfica sem as degradar; de um modo inverso, em Parque Jurássico, os dinossauros que vêm do passado foram criados por imagens de computador sistematicamente degradadas. (Manovich, 2001: 204)

Mas, apesar de durante algum tempo as definições afectas à desfocagem e à focagem terem sido necessárias para engendrar tanto remissões a períodos cronológicos do passado, como projecções para cenários futuristas, temos cada vez mais entre mãos tecnologias capazes de produzir imagens com escalas e graus de definição absolutamente surpreendentes. Tal poderá, à partida, permitir-nos antever que, assim que os seus usos científicos e artísticos se expandam aos media e às indústrias de entretenimento, i.e., às populares imagens do presente, seja possível que se venha a registar um gradual ajustamento dos padrões e convenções do realismo às imagens de alta definição. São vários os registos que dão conta da progressiva vinculação das imagens "do presente" à alta definição. Reportando-se a uma experiência de visionamento nos encontros iGrid 2005 de uma curta-metragem filmada em vídeo digital 4K, Lev Manovich (2005) descreve deste modo as imagens que viu:

Mesmo os mais prosaicos objectos ou as mais lisas e desinteressantes superfícies adquirem uma qualidade preciosa na medida em que é tornada visível a luz captada e reflectida pelas suas microestruturas. O efeito equivale a como se visse o mundo pela primeira vez, depois de ter sido lavado e limpo pela chuva. A comparação que me surge é com a pintura holandesa do século XVII: retratos, naturezas-mortas e interiores. (...) Nas mãos certas, o vídeo digital 4K torna-se capaz de criar uma representação semelhante do mundo. Atinge o efeito poético não escondendo os detalhes em sombras ou neblinas mas apresentando-os todos - e deixando os nossos olhos deliciarem-se a comparar padrões e texturas.

Para além das manifestas vantagens de resolução das novas aplicações de compactação da informação visual, os suplementos de realismo estão também a ser orientados para a viabilização de projecções das imagens em muito grandes formatos, assim como para a aceleração da velocidade de streaming, i.e., de transferência em tempo real de pacotes de ficheiros de alta qualidade. E aqui - nestes "suplementos" - parece-nos que alguns dos efeitos específicos dos media anteriores, tais como a "grande tela" do cinema ou o directo televisivo, efeitos por excelência de realismo e de imersão, encontraram novos e capazes sucessores.

Neste cenário da muito alta definição é mais do que provável a gradual perda de peso da linguagem das lentes e dos seus respectivos ruídos. Hoje imaginamos que num 
tempo de imagens ultradefinidas e processadas algoritmicamente haverá lugar para um contínuo desprendimento em relação ao contacto fundador de que, de alguma forma, os ruídos analógicos ainda guardam memória. Nesse momento estaríamos bem melhor resguardados desse toque do desconhecido que Kevin Robins (1996) reconheceu como a experiência mais receada pelo homem, e de que a imagem sempre o defendeu. Mas de facto o que as novas tecnologias da imagem digital virão fornecer não são tanto meios para um progressivo distanciamento do mundo, para uma espécie de ruptura, perda de corpo ou desrealização da imagem. O que está em causa é a preparação de um novo realismo em que a definição e a precisão visual estejam ao nível algorítmico, ou seja, matemático.

Contudo, não será totalmente improvável que a este novo realismo passem a estar associados outros níveis de ruído, agora relacionados com os ambientes da imagem computacional. $\mathrm{Na}$ verdade, interferências relacionadas com os processos de compressão e de transmissão, com o processamento de sinais e com a sua reprodução, com a incompatibilidade de softwares, a exposição a vírus, a inadequação das placas gráficas e das larguras de banda, entre muitas outras, já nos são suficientemente familiares na medida em que - e nem sempre pelas melhores razões - fazem parte da cultura digital. Ao contrário do discurso da sua indústria, a qualidade das imagens digitais raramente é perfeita, e tal sucede precisamente porque a função degradação foi incorporada no seu "código genético" e é parte activa no seu desenvolvimento. A questão merecerá inclusive ser colocada a outro nível: até quando estes novos “sinais indesejados” continuarão a ser apenas sentidos como interferências com a comunicação? Se de algum modo já são testemunháveis algumas aplicações artísticas que os incorporaram (designadamente no campo da webart e da arte digital, onde a pixelização mais se terá estilizado) como mote de exploração dos elementos “específicos” à linguagem do meio virtual, não será arriscado imaginarmos o seu peso na consolidação de um próximo realismo visual. De algum modo, a cultura da mediação tem dado provas de reconhecimento de que nem sempre será verdade que os media "ruidosos" sejam menos transparentes e verosímeis. No que mais particularmente diz respeito ao campo visual, essas informações (ou "reverberações") sobre o próprio medium e sobre o ambiente de comunicação onde ele incide parecem, de facto, já fazer parte convencionada de um determinado modo técnico de ser imagem. E, acima de tudo, de esta se fazer entender enquanto tal.

\section{Referências bibliográficas}

Aumont, J. (1995) L'Oeil interminable, Paris: Nouvelles Éditions Séguier.

Barboza, P. (1996) Du photographique au numérique. La parenthèse indicielle dans l'histoire des images, Paris: L'Harmattan.

Bazin, A. (1958) “A evolução da linguagem cinematográfica” in André Bazin, O que é o Cinema?, Lisboa: Livros Horizonte (1992): 71-89.

Bolter, J. D. \& Grusin, R. (2000) Remediation - Understanding New Media, Cambridge, Massachusetts: The MIT Press.

Bordwell, D. (1988) “Deep-focus Cinematography” in Bordwell, D., Staiger, J. \& Thomson, K. The Classical Hollywood Cinema. Film Style \& Mode of Production to 1960, London: Routledge: 341-352.

Comolli, J.-L. (1971) «La profondeur de champ “primitive” " in Cahiers du cinéma, n. . 233: 39-45. 
_ (1972) "Effacement de la profondeur/avènement de la parole" in Cahiers du cinéma, n. ${ }^{\text {os }}$ 234-235: 94-100.

Eco, U. (1989) A Obra Aberta, Lisboa: Difel.

Joly, M. (2003), A Imagem e a Sua Interpretação, Lisboa: Edições 70.

Manovich, L. (2001) The Language of New Media, Massachusets: The MIT Press.

(2005) Info-aesthetics [http://www.manovich.net acedido em 09.06.2008]

McLuhan, M. (1996) Comprender los medios de comunicación. Las extensiones del ser humano, Barcelona: Paidós.

Robins, K. (1996) "The Touch of the Unknown" in Robins, K. Into the Image: Culture and Politics in the Field of Vision, Londres: Routdlege: 11-34.

Thornburn, D. \& Jenkins, H. (eds.) (2003) Rethinking Media Change. The Aesthetics of Transition, Massachusetts: MIT Press.

Winston, Brian (1996) Technologies of Seeing. Photography, Cinematography and Television, Londres: British Film Institute.

Wolton, D. (1994), Elogio do Grande Público. Uma teoria crítica da televisão, Porto: Edições Asa. 